\title{
Raman probe for the simultaneous measurement of anion concentration in mixtures of salt solutions
}

\author{
Thomas H. Kauffmann, Kawther Ben Mabrouk and Marc D. Fontana \\ University of Lorraine and Supélec \\ Laboratoire Matériaux Optiques, Photonique et Systèmes - EA 4423 \\ Metz, France \\ thomas.kauffmann@metz.supelec.fr
}

\begin{abstract}
We propose to detect by Raman spectrometry the presence of several anions in mixtures of salt solutions and to measure simultaneously their respective concentrations. In this study we show how chemometric methods based on statistical analysis like Principal Components Analysis (PCA) and Partial Least Square Regression (PLSR) can be applied for the spectra treatment. Unlike current water probes often based on conductivity, our new Raman sensor is able to identify simultaneously and in one single measurement several anions such as $\mathrm{NO}_{3}{ }^{-}, \mathrm{SO}_{4}{ }^{2-}, \mathrm{HPO}_{4}{ }^{2-}$ or $\mathrm{Cl}^{-}$sought for the water pollution monitoring. Moreover our sensor gives rise to reliable, accurate and fast measurement (a few seconds) and can therefore be very useful for in situ water quality control applications.
\end{abstract}

\section{INTRODUCTION}

Several salts like nitrates and phosphates are frequently used in agriculture as fertilizers and are increasingly present in ground waters, basins or rivers. Moreover, other salts, and particularly chlorides, are used as de-icers during winter and can also be found in large quantities in waters. These salts in ionic form have a negative impact on the environment causing the eutrophication of lakes and the destruction of eco-systems [1]. Currently, several methods are available to detect and measure the concentration of these ions in solutions. In one hand are the electroanalytical sensors [2] measuring a voltage, a current or impedance, which allow to carry out in-situ measurements but can usually measure only one ion at a time using a specific electrode $\left(\mathrm{NO}_{3}^{-}, \mathrm{Cl}^{-}, \ldots\right)$ by comparison with a reference electrode. On the other hand, there are laboratory analysis methods like chromatography for example [3] which give more accurate results but require sampling and a long recording time measurement.

Here Raman spectrometry (RS) is proposed as new probe for the simultaneous detection of several salts diluted in water and the determination of theirs concentrations [4]. RS is a well know optical technique generally used to study the vibration of molecular bonds [5]. Based on the inelastic diffusion of the light by a materials, RS provides several information about the sample which can be a solid, a liquid or a gas. Thus, the different parameters related to a specific Raman line (position, intensity, full width at half maximum) give indications about the sample [6,7] like the molecular composition used to identify species (ions in solution in our case) thanks to the lines positions or the concentrations related to the peaks intensities. RS is particularly adapted for liquid analysis, allowing fast and in-situ measurements (no sampling) and gives rise to a simultaneous detection of several ions in solutions. Moreover, RS associated with chemometric methods [8] gives rise to an efficient probe for water monitoring.

\section{MATERIAL AND METHOD}

\section{A. Raman spectrometry and salt solutions}

Raman spectrometry consists in exciting a material with a laser and collecting the light diffused by it. Indeed, although the majority of the scattered light does not exchange energy with the material i.e. no change in wavelength (Rayleigh scattering), a small part of the light interacts with the sample and has therefore a different wavelength (inelastic scattering). This is the Raman scattering which highlights vibration modes of the molecules. A Raman spectrum therefore provides a fingerprint of the molecular bonds of a material and the study of its evolution or its modification provides information about the sample (bonds, concentration, temperature, mechanical stress etc.). Here Raman spectrometry is used as a probe for the detection and the measurement of salt diluted in water with all the advantages of this technique: use of contacless or immersion probe, no sample preparation, in-situ and fast measurement.

Analysis of Raman spectra of salts diluted in water shows a modification of the water spectrum by the anions present in the solution (the $\mathrm{OH}$ stretching band in particular) and characteristic peaks [9]. Some of these ions have a specific signature in the wavenumber range around $1000 \mathrm{~cm}^{-1}(30$ $\mathrm{THz}$ ). For example, the line located at $981 \mathrm{~cm}^{-1}$ is specific to the sulfate anion $\mathrm{SO}_{4}{ }^{2-}$ and the line at $1048 \mathrm{~cm}^{-1}$ to the nitrate anion $\mathrm{NO}_{3}^{-}$. In addition to being indicators of the type of ions present in solution, these peaks evolve in intensity with the concentration of the species so that a calibration can be usually done for each anion [4]. Moreover, other salts such as chlorides [10] do not exhibit specific lines (not active in Raman) but just slightly disturb the wide O-H stretching band of the water spectrum around $3500 \mathrm{~cm}^{-1}$ so that the determination of the concentration is still possible but more difficult in this case $[11,12]$. 


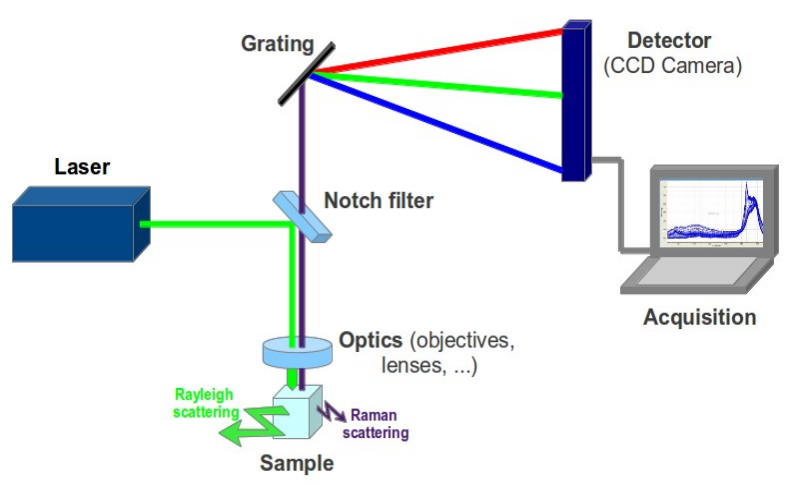

Figure 1. Raman instrumentation.

\section{B. Instrumentation}

Several salted solutions (pure and mixtures) at different concentrations of nitrate, sulfate, phosphate and chloride were prepared by weight. Spectra were recorded in 5 seconds at room temperature with a RXN-1 Raman spectrometer (Kaiser Optical Systems). As shown in Fig. 1, an excitation laser line at $532 \mathrm{~nm}$ was used and the laser light was focused through a $10 \times$ objective at a distance above $1 \mathrm{~cm}$ from the liquid sample contained in a quartz cell. The Raman light is collected in backscattering configuration by the same optic, filtered to overcome the Rayleigh line and is diffracted through a grating on a CCD camera (Andor) using two lines of 1024 pixels and cooled at $-40{ }^{\circ} \mathrm{C}$. Acquisition was done by the iCRaman software (Mettler Toledo) and the spectral range starts at 100 $\mathrm{cm}^{-1}$ and ends at $4350 \mathrm{~cm}^{-1}$ within a spectral resolution of 2 $\mathrm{cm}^{-1}$. Signal processing and chemometric analysis (PCA and PLSR) were performed according to a self-made program using the $\mathrm{R}$ language [13].

\section{Principal components analysis}

Chemometric analysis includes all the statistical and mathematical methods for extracting information from a spectrum $[14,15]$. Generally based on the analysis of a large number of data, several methods are used to rank the spectra in order to sort the corresponding species. Others methods are used to link the spectra evolution with species concentration to establish a calibration law. Chemometric analysis is widely used in IR spectroscopy [16] and more and more in Raman studies $[8,17]$.

Here we use the principal components analysis (PCA) in order to detect the presence of several anions in a mixture of salt solutions. The principle of a PCA is to reduce the number of spectral variables using an orthogonal transformation and turn them into uncorrelated variables called principal components (PC) ranked in order of largest possible variance. The interest of a PCA is that the number of principal components is very small (generally less than 10) compared to the large number of original variables. In this study, Raman spectra have 2048 spectral variables i.e. intensities, which are reduced by PCA to scores and loadings. Scores are the coordinates of each spectrum in the different dimensions (principal components) and loadings are the representation of these dimensions according to the wavenumbers. The distribution of these scores in the space of dimensions is used to group individuals (spectra) according to common principal components and thus to link them to a physical or chemical parameter. This "scores plot" allows highlighting similarities between spectra according principal components. It is a very useful tool to class or group spectra and therefore the related species. If individuals are uniformly distributed along one of these dimensions, it is possible to perform a regression on this component (PCR for principal components regression) in order to establish a calibration model.

\section{PLS regression and evaluation}

Partial Least Square Regression (PLSR) is another regression method developed by Wold in the 1960s [15] more powerful than the PCR and widely used in spectrometric application (infrared or Raman) for quantitative analysis. PLS regression works in the same way as the PCA but take into account the response values e.g. species concentrations and their variations, in the determination of the calibration model.

The efficiency of a regression can be evaluated by different methods and criteria. Here, three criteria were used: the regression coefficient $R^{2}$, the root mean square error RMSE and the bias BIAS. The regression coefficient corresponds to the spreading predictions parallel to the ideal line. $\mathrm{R}^{2}$ is usually given for a regression but this parameter although necessary is not sufficient. It is important to consider other several parameters as the RMSE and the bias for example in order to evaluate a regression model. Thus, the RMSE measure the differences between values predicted by the model and the observed value and has the same unit as the predicted value. The bias allows the identification of an offset on the prediction. If the bias is negative the true values are underestimated and overestimated if positive.

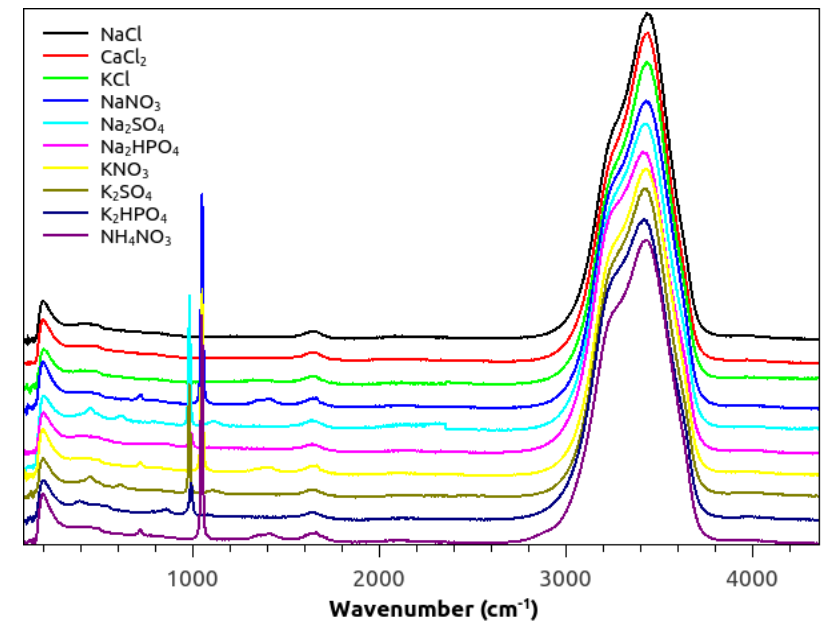

Figure 2. Raman spectra of several salt solutions (deliberately shifted) showing characteristic lines of $\mathrm{NO}_{3}{ }^{-}, \mathrm{SO}_{4}{ }^{2-}$ and $\mathrm{HPO}_{4}{ }^{2-}$ anions around $1000 \mathrm{~cm}^{-1}$ and the wide $\mathrm{OH}$ stretching band of the water centered at 3500 $\mathrm{cm}^{-1}$ and affected by the $\mathrm{Cl}^{-}$anion. 


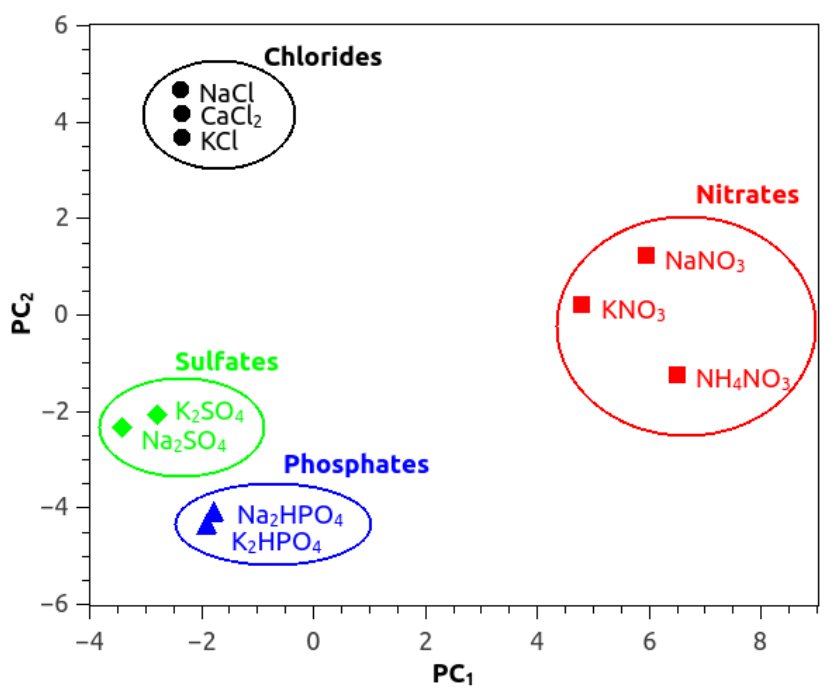

Figure 3. Scores plot resulting from a PCA on several pure salt solutions of nitrates, sulfates, phosphates and chlorides.

\section{RESULTS AND DISCUSSION}

\section{A. Ion identification}

In this study several salt solutions of nitrates $\left(\mathrm{NaNO}_{3}\right.$ and $\left.\mathrm{KNO}_{3}\right)$, sulfates $\left(\mathrm{K}_{2} \mathrm{SO}_{4}\right.$ and $\left.\mathrm{Na}_{2} \mathrm{SO}_{4}\right)$, phosphates $\left(\mathrm{Na}_{2} \mathrm{HPO}_{4}\right.$ and $\left.\mathrm{K}_{2} \mathrm{HPO}_{4}\right)$ and chlorides $\left(\mathrm{NaCl}, \mathrm{CaCl}_{2}\right.$ and $\left.\mathrm{KCl}\right)$ were prepared and their Raman spectra were recorded under the same experimental conditions and normalized by the SNV method (Standard Normal Variate) (see Fig. 2). A PCA taking into account 5 principal components was applied on the set of spectra. Scores plot resulting of the projection of the different spectra according to the two first principal components $\mathrm{PC}_{1}$ and $\mathrm{PC}_{2}$ is given in Fig. 3.

One can see that a PCA allows classing the spectra in several clusters according to the type of anion: $\mathrm{NO}_{3}{ }^{-}, \mathrm{SO}_{4}{ }^{2-}$, $\mathrm{HPO}_{4}{ }^{2-}$ and $\mathrm{Cl}^{-}$. Because of the intense peak of $\mathrm{NO}_{3}{ }^{-}$at this concentration compared to the lines of the other polyatomic anions $\left(\mathrm{SO}_{4}{ }^{2-}\right.$ and $\left.\mathrm{HPO}_{4}{ }^{2-}\right) \mathrm{PC}_{1}$ mainly reflects the influence of the nitrate ion. In the same way, chlorides which do not have any specific lines but affect the $\mathrm{O}-\mathrm{H}$ band more strongly than polyatomic ions is more represented by the second components $\mathrm{PC}_{2}$. Sulfates and phosphates which both give lines and affect the $\mathrm{O}-\mathrm{H}$ stretching band are placed according to the two dimensions but can also be easily distinguished.

\section{B. Prediction models}

In order to built prediction models for these anions, a PLS analysis was applied on several salt solutions with different anion concentrations given in $\mathrm{mol} / \mathrm{l}$. So 32 chlorides solutions with concentrations from 0 up to $4.02 \mathrm{~mol} / \mathrm{l}, 17$ nitrates solutions from 0 up to $624 \mathrm{mmol} / \mathrm{l}, 18$ sulfates solutions from 0 up to $704 \mathrm{mmol} / \mathrm{l}$ and 17 phosphates solutions from 0 up to $574 \mathrm{mmol} / \mathrm{l}$ were prepared and used in this work. Moreover in order to evaluate the quality of the model established for each anion, a cross validation is done using the "leave-one-out" method. Results of the PLS regression showing values of $R^{2}$,
RMSE and BIAS are given in Tab. I for each anion in calibration and validation. RMSE and BIAS are expressed in mmol/l. Curves for $\mathrm{Cl}^{-}$and $\mathrm{NO}_{3}{ }^{-}$are given as example in Fig. 4.

Results show that a good prediction model can be established whatever the type of anion. Thus, PLS analysis on polyatomic anions with their specific signatures around 1000 $\mathrm{cm}^{-1}$ gives good calibration models according to $\mathrm{R}^{2}>0.99$ and $\mathrm{RMSE}<5 \mathrm{mmol} / \mathrm{l}$ in each case i.e. less than $1 \%$ considering the full concentration range. Moreover, although chlorides just slightly affect the water spectrum, PLS method allows a good calibration model for this anion with $\mathrm{R}^{2}>0.999$ and a RMSE of $12.6 \mathrm{mmol} / 1$, also less than $1 \%$. We remind that results in validation are always worse than in calibration. Here validation results can be considered as good with high $\mathrm{R}^{2}$ in all cases and RMSE less than $30 \mathrm{mmol} / 1$ i.e. $2.5 \%$ for the phosphate anion and $1 \%$ for the others.

TABLE I. RESULTS OF PLS REGRESSION MADE ON NITRATES, SULFATES, PHOSPHATES AND CHLORIDES SOLUTIONS.

\begin{tabular}{|c|c|c|c|c|c|c|}
\hline & \multicolumn{3}{|c|}{ Calibration } & \multicolumn{3}{c|}{ Validation } \\
\hline Anion & $\boldsymbol{R}^{2}$ & $\boldsymbol{R M S E}$ & $\boldsymbol{B I A S}$ & $\boldsymbol{R}^{2}$ & $\boldsymbol{R M S E}$ & $\boldsymbol{B I A S}$ \\
\hline $\mathrm{NO}_{3}{ }^{-}$ & 0.9982 & 4.3 & 0 & 0.9966 & 5.9 & 0.07 \\
\hline $\mathrm{SO}_{4}{ }^{2-}$ & 0.9983 & 4.0 & 0 & 0.9940 & 7.5 & -0.1 \\
\hline $\mathrm{HPO}_{4}{ }^{2-}$ & 0.9974 & 4.4 & 0 & 0.9733 & 14.2 & 0.6 \\
\hline $\mathrm{Cl}^{-}$ & 0.9998 & 12.6 & 0 & 0.9994 & 27.3 & -0.9 \\
\hline
\end{tabular}
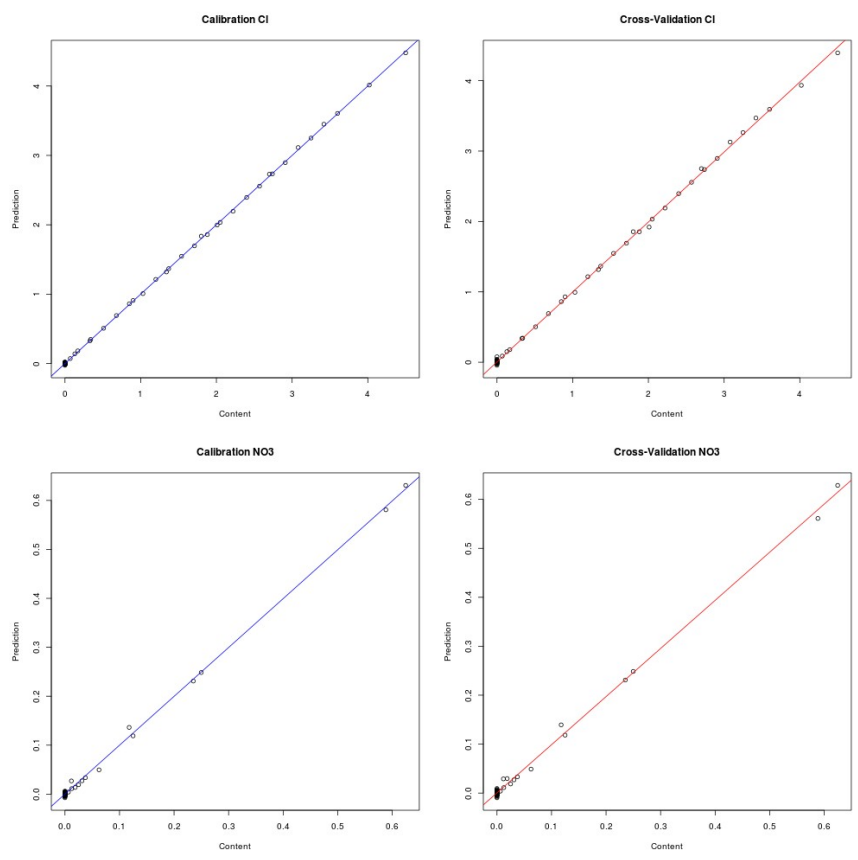

Figure 4. Calibration and validation curves for $\mathrm{Cl}^{-}$and $\mathrm{NO}_{3}{ }^{-}$anions resulting from a PLS analysis. 


\section{Salt mixture analysis}

Now that prediction models have been built for each anion, we are able to analyze salt solutions. For this, several solutions were prepared and the previous chemometric methods have been applied on their Raman spectra. Sample $n^{\circ} 1$ corresponds to pure water, samples $n^{\circ} 2$ and $n^{\circ} 3$ to pure salt solutions of chloride and nitrate respectively, and samples $n^{\circ} 4$ and $n^{\circ} 5$ are mixtures of several salts. Results of the PLS analysis is given in Tab. II.

First, the method allows a very good concentration prediction on pure solutions with an error (difference between predicted and real concentrations) less than $10 \mathrm{mmol} / 1$ (sample $n^{\circ} 1, n^{\circ} 2$ and $n^{\circ} 3$ ). Then, the method gives also good results on salt mixtures (sample $n^{\circ} 4$ and $n^{\circ} 5$ ) although prediction errors are higher, ranging from 10 to more than $150 \mathrm{mmol} / 1$ sometimes. The determination of phosphate content is not completely satisfactory compared to the detection of the other anions. This is likely due to a less sensitivity of phosphate in both the direct Raman signature and the $\mathrm{O}-\mathrm{H}$ band, as revealed by the scores of this anion in Fig. 3.

TABLE II. ANION CONCENTRATION PREDICTION OF PURE AND MIXTURES SALT SOLUTIONS.

\begin{tabular}{|c|c|c|c|c|c|c|c|c|}
\hline & \multicolumn{4}{|c|}{ Concentration $(\mathrm{mmol} / \mathrm{l})$} & \multicolumn{4}{|c|}{ Prediction (mmol/l) } \\
\hline Sample & $\mathrm{Cl}^{+}$ & $\mathrm{NO}_{3}^{-}$ & $\mathrm{SO}_{4}^{2-}$ & $\mathrm{HPO}_{4}^{2-}$ & $\mathrm{Cl}^{-}$ & $\mathrm{NO}_{3}^{-}$ & $\mathrm{SO}_{4}^{2-}$ & $\mathrm{HPO}_{4}{ }^{2-}$ \\
\hline $\mathrm{n}^{\circ} 1$ & 0 & 0 & 0 & 0 & 1 & 7 & 3 & 4 \\
\hline$n^{\circ} 2$ & 510 & 0 & 0 & 0 & 502 & 1 & 2 & 5 \\
\hline $\mathrm{n}^{\circ} 3$ & 0 & 625 & 0 & 0 & 1 & 630 & 3 & 4 \\
\hline$n^{\circ} 4$ & 510 & 620 & 430 & 380 & 543 & 832 & 479 & 507 \\
\hline$n^{\circ} 5$ & 428 & 294 & 176 & 143 & 463 & 304 & 184 & 1 \\
\hline
\end{tabular}

\section{CONCLUSION}

Raman spectrometry can be a very useful tool for water analysis. Thus this optical technique is able to quickly and simultaneously detect and measure several substances dissolved in water like nitrates, sulfates, phosphates and chlorides sought for water quality control. We have shown in this paper that chemometric analysis can differentiate anions in solutions making it easier to detect the presence of species that do not have characteristic peaks but slightly influence the spectrum of water like the chlorides. PLS regressions applied on several salt spectra give rise to good calibration models allowing predicting the concentration of each anion, even in salt mixture solutions simultaneously.

\section{REFERENCES}

[1] N. Berenzen, R. Schulz, M. Liess, "Effects of chronic ammonium and nitrite contamination on the macroinvertebrate community in running water microcosms," Water Research, 35 :3478-3482, 2001.

[2] R. Bhadekar, S. Pote, V. Tale, B. Nirichan, "Developments in analytical methods for detection of pesticides in environmental samples," American Journal of Analytical Chemistry, 2 :1-15, 2011.

[3] C.A. Lucy, "Recent advances in ion chromatography: A perspective," Journal of Chromatography A, $739: 3-13,1996$.

[4] M.D. Fontana, K. Ben Mabrouk, T.H. Kauffmann, "Raman spectroscopic sensors for inorganic salts," in J. Yarwood, R. Douthwaite, S. Duckett, editor, Spectroscopic Properties of Inorganic and Organometallic Compounds, 44 :40-67, RSC Publishing, 2013.

[5] L.A. Lyon et al., "Raman spectroscopy," Anal. Chem., 70 :341R-361R, 1998.

[6] Ph. Colomban, "Imagerie Raman de matériaux et dispositifs hétérogènes," Techniques de l'Ingénieur, 04 :RE 5 1-13, 2002.

[7] J. Barbillat et al., "Spectrométrie Raman," Techniques de l'Ingénieur, P2-865 : 1-31

[8] O. Svensson, M. Josefson, F.W. Langkilde, "Reaction monitoring using Raman spectroscopy and chemometrics," Chemometrics and Intelligent Laboratory Systems, 49 :49-66, 1999.

[9] K. Ben Mabrouk, T.H. Kauffmann, H. Aroui, M.D. Fontana, "Raman study of cation effect on sulfate vibration modes in solid state and in aqueous solutions," Journal of Raman Spectroscopy, in press.

[10] K. Furic, I. Ciglenecki, B. Cosovic, "Raman spectroscopic study of sodium chloride water solutions," Journal of Molecular Structure, 550-551:225-234, 2000.

[11] S.A. Burikov, T.A. Dolenko, V.V. Fadeev, A.V. Sugonyaev, "New opportunities in the determination of inorganic compounds in water by the method of laser Raman spectroscopy," Laser Physics, 15(8) : 1175-1179, 2005.

[12] T.H. Kauffmann, M.D. Fontana, "Optical sensor of salt concentration: Uncertainty evaluation," Sensors and Actuators B: Chemical, 161 : 21-27, 2012.

[13] R Core Team (2012). R: A language and environment for statistical computing. R Foundation for Statistical Computing, Vienna, Austria. ISBN 3-900051-07-0, URL http://www.R-project.org/.

[14] S. Wold, "Chemometrics; what do we mean with it, and what do we want from it?," Chemometrics and Intelligent Laboratory Systems, 30 : 109-115, 1995.

[15] S. Wold and M. Sjostrom, "Chemometrics, present and future success", Chemometrics and Intelligent Laboratory Systems, , 44 :3-14, 1998.

[16] C. Muehlethaler, G. Massonnet, P. Esseiva, "The application of chemometrics on Infrared and Raman spectra as a tool for the forensic analysis of paints," Forensic Science International, 209 :173-182, 2011.

[17] J.B. Cooper, "Chemometric analysis of Raman spectroscopic data for process control applications," Chemometrics and Intelligent Laboratory Systems, $46: 231-247,2009$. 